\title{
Rate of smoking cessation and factors associated with successful quit smoking in Seremban District of Malaysia
}

\author{
Mohd Ammar Ihsan Ahmad Zamzuri ${ }^{\mathrm{a}}$, Syuaib Aiman Amir Kamarudin ${ }^{\mathrm{b}}$, Ahmad Husni Ariffin ${ }^{\mathrm{b}}$, \\ Ariff Azfarahim Ibrahim ${ }^{\mathrm{a}}$, Mohd Hairil Othman ${ }^{\mathrm{b}}$, Asmah Johari ${ }^{\mathrm{b}}$, Noor Khalili Mohd Ali ${ }^{\mathrm{b}}$, \\ Kavita Jetly ${ }^{\mathrm{a}}$, Mohamad Faid Abd Rashid ${ }^{\mathrm{c}}$, Mohd Rohaizat Hassan ${ }^{\mathrm{a}}$, Sim Si Ming ${ }^{\mathrm{d}}$, \\ Nicholas Tze Ping Pang d," \\ a Department of Community Health, Universiti Kebangsaan Malaysia, Jalan Yaacob Latif, Bandar Tun Razak, 56000, Wilayah Persekutuan, Kuala Lumpur, Malaysia
b Seremban District Health Office, Jalan Lee Sam, Bandar Seremban, 70590, Seremban, Negeri Sembilan, Malaysia
c State Department of Health Negeri Sembilan, Jalan Rasah, Bukit Rasah, 70300, Seremban, Negeri Sembilan, Malaysia
${ }^{\mathrm{d}}$ Universiti Malaysia Sabah, Jalan UMS, 88400, Kota Kinabalu, Sabah, Malaysia
}

A R T I C L E I N F O

\section{Keywords:}

Smoking

Quit

Cessation

Stop

Factors associates

Predictors

Clinic

\begin{abstract}
A B S T R A C T
Introduction: Smoking is a major public health significant and a leading preventable cause of premature mortality. Assisting smoking cessation is important due to potential positive health impacts. The establishment of "Quit Smoking Clinics" reflect a great commitment by the health authority to reduce the national burden of smoking prevalence.

Aim: The objective is to measure the prevalence of smoking cessation and factors associate with successful quit smoking in all public healthcare "Quit Smoking Clinic" in Seremban district, Malaysia.

Method: This retrospective cross-sectional study uses registry data and clinical notes from public healthcare clinics in Seremban district from January 2019 to June 2019. The outcome of interest was the proportion of smokers that enrolled in "Quit Smoking Clinic" who remained abstinent at six months of follow-up. Multivariate analysis was done to determine the predictors for successful smoking cessation in the study.

Result: Out of the 285 smokers included in this study, 86 smokers (30.2\%) quit smoking in this programme. Significant predictors of quitting smoking were use of nicotine replacement therapy (NRT), frequency of attending the appointments, presence of diabetes comorbidity, and Malay ethnicity. The Hosmer test showed a good model fit (p-value 0.998) and area under the curve (AUC) was 0.96\% (95\% CI 0.94-0.98) in the receiver operating characteristic (ROC) curve.

Conclusion: The "Quit Smoking Clinic" programme showed good outcome and the service should be expanded to the private sector. Predictors for smoking cessation identified can be used by policy makers to design more targeted approaches, ensuring more smokers quit smoking.
\end{abstract}

\section{Introduction}

Smoking remains a public health threat though it can be prevented. The World Health Organisation (WHO) reported around 8 million people a year succumbed to death due to smoking, with current estimated numbers of 1.3 billion smoker worldwide. ${ }^{1}$ In addition, almost $80 \%$ of them live in low-and-middle income countries. In Malaysia, the prevalence of smoking has plateaued over three decades; the prevalence remained steady at $24.8 \%$ in $1996,21.5 \%$ in 2006 , and $22.8 \%$ in 2015 among the population. ${ }^{2}$ The reasons there was a small increase between 2006 and 2015 are as yet unknown, but one postulated factor is the increase in smoking rates amongst previously non-smoking groups, namely women and adolescents.

The harmful health effects of smoking is well known and have been documented in numerous epidemiological studies. The devastating negative impacts are not only seen among smokers, but in non-smoker

\footnotetext{
* Corresponding author.

E-mail addresses: ihsan.zamzuri@gmail.com (M.A.I.A. Zamzuri), syuaibaiman97@gmail.com (S.A.A. Kamarudin), hiusfey@gmail.com (A.H. Ariffin), ariff131@

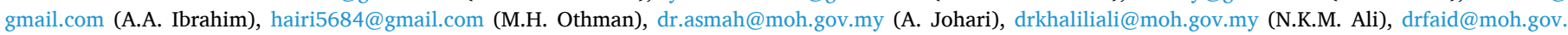
my (M.F. Abd Rashid), rohaizat@ppukm.ukm.edu.my (M.R. Hassan), bm19110070@student.ums.edu.my (S.S. Ming), nicholas@ums.edu.my (N.T.P. Pang).
} 
due to second hand smoke exposure. The mechanism by which smoking causes diseases involves multiple complex pathways such as exposure to free radicals from the components of tobacco smoke that subsequently lead to increased oxidative stress, inflammation, and DNA damage. ${ }^{3}$ Nonetheless, other chemical toxins that are present in cigarettes can be transported to nearly every part of the body, thus exerting carcinogenic effects. ${ }^{4}$ The causal relation between smoking and cancers of the head, neck, liver, bladder, cervix, oesophagus, colon, and rectum has been well documented in the literature. In addition, smoking is also associated with the development of chronic pulmonary diseases such as chronic obstructive pulmonary disease and is known to exacerbate asthma. $^{5}$

Although prevention of smoking initiation is of paramount importance, quitting from current smoking status is equally crucial. The need for smoking cessation stems from its potential benefit gained. Besides enjoying better quality of life, the cardiocirculatory function will improve immediately, injured lungs start to heal within 1 year, and the risk of developing coronary diseases and cerebral accidents halves. ${ }^{1,6}$ In view of the direct and indirect impact of smoking towards burdens of disease as well as the benefit gained from smoking cessation, Malaysia as well as other countries has signed a declaration to accelerate "hard-hitting" measures to reduce tobacco use under the document called the Framework Convention on Tobacco Control (FCTC) led by WHO. ${ }^{7}$ One of the outlined measures is offering help to quit smoking. ${ }^{8}$ In response to this, the Malaysian Ministry of Health ( $\mathrm{MOH}$ ) has launched a range of initiatives through various platforms including collaboration with other government agencies, as well as through community empowerment, such as Komuniti Sihat Pembina Negara (KOSPEN; loosely translated to "Healthy Community Builds the Nation"). Within the MOH itself, Quit Smoking Clinics have been established to ensure the availability of the service in the community is free of charge. ${ }^{9}$ Quit Smoking Clinics were set up by central government in 2011, offering pharmacological (nicotine patches and Nicorette) and psychological treatment (motivational interviewing) for quitting smoking. Such clinics are part of pre-existing government health clinics, and usually contain a medical officer, a nurse, a medical assistant, and a trained counsellor where possible. Individuals are referred and follow an algorithm lasting 24 weeks, with a combination of in-person and telephone treatment offered. ${ }^{9}$

Apart from counselling and pharmacological treatment, identifying factors associated with successful smoking cessation is imperative to enhance the smoking cessation rate. Evidence shows that multiple factors can predict successful quit smoking outcomes. Among the predictors are; smokers who are in the elderly age group, married status, have junior or high school education, higher income, smoking less than 20 cigarettes per day, delayed involvement in smoking, perception of one's health as good or excellent, and lower level of stress, are more likely to quit smoking. ${ }^{10}$ However, to the best of the authors' knowledge there is no local evidence, at specific district level, determining predictors for smoking cessation. Conducting localised situational analyses is crucial especially as the population of Malaysia (generally) and Seremban district (specifically) is so diverse racially and culturally. Through identification of localised predictors for smoking cessation, policy makers can formulate more targeted approach that will yield higher quit smoking rates. The aims of this study is hence to describe the prevalence and factors associated with smoking cessation among clients attending the public "Quit Smoking Clinic" in Seremban District, Malaysia, throughout the year 2019 .

\section{Methods}

\subsection{Study design}

This is a retrospective cross sectional study. Data were obtained through examining records of all smokers who attended "Quit Smoking Clinics" in all 12 public health facilities in Seremban district, from January 2019 to June 2019. The authors (MAIAZ, SAAK, AHA \& AAI) extracted the data from all the case notes for every visit and follow-up. Any discrepancy of information was verified with the medical personnel in charge.

\subsection{Sample and procedure}

The samples were smokers who attended clinics who had either been self-referred or had been referred by their doctors from out-patient clinics or Non-Communicable Disease clinic. The "Quit Smoking Clinics" have designated and trained health personnel with competence in the module to assist smokers to quit smoking. They are also trained to provide brief intervention and free nicotine replacement therapy (NRT). Each smoker was assessed at the point of first contact, provided with health education, and a quit date was fixed. They were encouraged to cease smoking either after the first or second visit. Follow-up sessions at their respective clinics are according to the recommendation i.e. once a week for the first month, every two weeks for the subsequent month, and once a month for follow-up from the third to sixth month.

\subsection{Measures}

All data in registry and clinical notes were available in either Malay or English. Socio-demographic characteristics included were age, gender, ethnicity, and locality status. As for smoking information, method of participation, quit date, treatment received, and frequency of appointments attended were retrieved. Other information included were comorbidities such as diabetes, hypertension and ischaemic heart disease. Our primary outcome was self-reported smoking status at six months follow-up. Those who did not attend follow-up at six month were assumed to be smoking.

\subsection{Statistical analyses}

Data was tabulated in Microsoft Excel while analysis was done using SPSS 21.0. Descriptive statistics were used to analyse the sociodemographic characteristics of smokers. Statistical test for association for continuous data was done using Independent T-test, while Chi Square test for categorical variable. In addition, multiple logistic regression was conducted among the variables with p-value $<0.25$ to determine significant predictors for successful quit smoking. ${ }^{11}$ Backward Likelihood Ratio (LR) method was used for the model and alpha value was set at 0.05 to reject null hypothesis. Subsequently the Hosmer and Lemishow test was conducted to look for model fitness.

\section{Ethical approval}

The study has been approved by the Medical Research \& Ethics Committee of the Ministry of Health Malaysia (MREC) and registered with the National Medical Research Register (NMRR).

\section{Result}

A total of 285 participants of "Quit Smoking Clinic" were included in this study. As Table 1 suggests, the majority of samples were male (96.4\%), of Malay ethnicity (67.7\%), residing in urban areas (74\%), and participating in the study following referral from their doctor (61.4\%) Hypertension was the commonest comorbidity (28.8\%) among smokers followed by diabetes $(11.9 \%)$ and ischaemic heart disease (IHD) with $4.9 \%$. In terms of quit smoking clinic interventions, as Table 2 suggests, only one third of participants were prescribed with nicotine replacement therapy (NRT). Only $10.5 \%$ of participants attended appointments between 7 and 9 times during the follow-up, while only $9.8 \%$ attended more than 10 times.

Our study found that $30.2 \%(n=86)$ of smokers successfully quit smoking within six month of follow-up. In bivariate analysis, as per Table 3, five factors showed a significant association with success of quit 
Table 1

Baseline characteristic of smokers in the program.

\begin{tabular}{|c|c|c|}
\hline Variable & $\mathrm{N}$ & $\%$ \\
\hline Age $^{\mathrm{a}}$ & $46.5(14.9)$ & - \\
\hline \multicolumn{3}{|l|}{ Gender } \\
\hline Male & 269 & 94.6 \\
\hline Female & 16 & 5.4 \\
\hline \multicolumn{3}{|l|}{ Ethnicity } \\
\hline Malay & 193 & 67.7 \\
\hline Chinese & 37 & 13 \\
\hline Indian & 53 & 18.6 \\
\hline Others & 2 & 0.7 \\
\hline \multicolumn{3}{|c|}{ Residence Locality } \\
\hline Urban & 211 & 74 \\
\hline Rural & 74 & 26 \\
\hline \multicolumn{3}{|c|}{ Co-morbidity } \\
\hline \multicolumn{3}{|c|}{ Hypertension } \\
\hline Yes & 82 & 28.8 \\
\hline No & 203 & 71.2 \\
\hline \multicolumn{3}{|l|}{ Diabetes } \\
\hline Yes & 34 & 11.9 \\
\hline No & 251 & 88.1 \\
\hline \multicolumn{3}{|c|}{ Ischaemic Heart Disease } \\
\hline Yes & 14 & 4.9 \\
\hline No & 271 & 95.1 \\
\hline
\end{tabular}

${ }^{\text {a }}$ Mean (SD).

Table 2

Behaviour at quit smoking clinics.

\begin{tabular}{lcl}
\hline Variable & $\mathrm{n}$ & $\%$ \\
\hline Mode of Participation & & \\
$\quad$ Voluntary & 110 & 38.6 \\
$\quad$ Referred & 175 & 61.4 \\
Treatment Nicotine Replacement & Therapy & \\
(NRT) & 87 & 30.5 \\
Non NRT & 198 & 69.5 \\
Frequency of Attended Appointments & \\
0 & 44 & 15.4 \\
1 to 3 & 132 & 46.3 \\
4 to 6 & 51 & 17.9 \\
7 to 9 & 30 & 10.5 \\
$\geq 10$ & 28 & 9.8 \\
\hline
\end{tabular}

smoking, namely age (p-value 0.0001); those with comorbidities hypertension ( $p$-value 0.0001), diabetes (p-value 0.01), ischaemic heart disease (p-value 0.035); and frequency of attended appointment ( $\mathrm{p}$ value 0.0001 ). In view of skewedness of data for ethnicity, the factor was collapsed into two classes (Malay and non-Malay).

All ten factors were included in multiple logistic regression. Four predictors were obtained from this model as suggested in Table 4. Smokers who were treated with NRT had almost three times higher odds of quitting smoking. Apart from that, diabetic smokers have four times higher odds of quitting smoking. In addition, those who attended "Quit Smoking Clinic" had more than ten times greater odds of successfully quit smoking. Nevertheless, our finding showed that Malay ethnicity had three times odds to achieve smoking cessation.

There was no multicollinearity detected among factors in the model (VIF value $<2$ ). The Nagelkerke, $r^{2}$ value for the model was $75.4 \%$ and Hosmer \& Lemeshow test showed model fitness (p-value 0.998). The
Table 3

Bivariate analysis.

\begin{tabular}{|c|c|c|c|c|c|c|}
\hline & Success & Fail & $\begin{array}{l}\text { Chi } \\
\text { Square }\end{array}$ & $\mathrm{df}$ & p-value & $\mathrm{N}$ \\
\hline Mean Age ${ }^{a}$ & $\begin{array}{l}13.80 \\
(51.63 \%)\end{array}$ & $\begin{array}{l}14.80 \\
(44.23 \%)\end{array}$ & 7.402 & 283 & $0.0001^{b}$ & - \\
\hline \multicolumn{7}{|l|}{ Gender } \\
\hline $\begin{array}{l}\text { Male } \\
\text { Female }\end{array}$ & $\begin{array}{l}30.9 \% \\
18.8 \%\end{array}$ & $\begin{array}{l}69.1 \% \\
81.3 \%\end{array}$ & - & - & $0.407^{c}$ & $\begin{array}{l}269 \\
16\end{array}$ \\
\hline \multicolumn{7}{|l|}{ Ethnicity } \\
\hline Malay & $\begin{array}{l}64 \\
(33.2 \%)\end{array}$ & $\begin{array}{l}129 \\
(66.8 \%)\end{array}$ & 1.579 & 1 & 0.13 & 193 \\
\hline Others & $\begin{array}{l}22 \\
(23.9 \%)\end{array}$ & $\begin{array}{l}70 \\
(76.1 \%)\end{array}$ & & & & 92 \\
\hline \multicolumn{7}{|l|}{ Locality } \\
\hline Urban & $\begin{array}{l}61 \\
(28.9 \%)\end{array}$ & $\begin{array}{l}150 \\
(71.7 \%)\end{array}$ & 0.618 & 1 & 0.463 & 211 \\
\hline Rural & $\begin{array}{l}25 \\
(33.8 \%)\end{array}$ & $\begin{array}{l}49 \\
(66.2 \%)\end{array}$ & & & & 74 \\
\hline \multicolumn{7}{|l|}{ Hypertension } \\
\hline Yes & $\begin{array}{l}39 \\
(47.6 \%)\end{array}$ & $\begin{array}{l}43 \\
(52.4 \%)\end{array}$ & 16.515 & 1 & 0.0001 & 82 \\
\hline No & $\begin{array}{l}47 \\
(23.2 \%)\end{array}$ & $\begin{array}{l}156 \\
(76.8 \%)\end{array}$ & & & & 203 \\
\hline \multicolumn{7}{|c|}{ Diabetes Mellitus } \\
\hline Yes & $\begin{array}{l}17 \\
(50.0 \%)\end{array}$ & $\begin{array}{l}17 \\
(50.0 \%)\end{array}$ & 7.201 & 1 & 0.01 & 34 \\
\hline No & $\begin{array}{l}69 \\
(27.5 \%)\end{array}$ & $\begin{array}{l}182 \\
(72.5 \%)\end{array}$ & & & & 251 \\
\hline \multicolumn{7}{|c|}{ Ischaemic Heart Disease (IHD) } \\
\hline Yes & $8(57.1 \%)$ & $6(42.9 \%)$ & - & - & $0.035^{c}$ & 14 \\
\hline No & $\begin{array}{l}78 \\
(28.8 \%)\end{array}$ & $\begin{array}{l}193 \\
(71.2 \%)\end{array}$ & & & & 271 \\
\hline \multicolumn{7}{|c|}{ Intake Participation } \\
\hline Volunteer & $\begin{array}{l}38 \\
(34.5 \%)\end{array}$ & $\begin{array}{l}72 \\
(65.5 \%)\end{array}$ & 1.624 & 1 & 0.233 & 110 \\
\hline Referral & $\begin{array}{l}48 \\
(27.4 \%)\end{array}$ & $\begin{array}{l}127 \\
(72.6 \%)\end{array}$ & & & & 175 \\
\hline \multicolumn{7}{|c|}{ No of attended appointment } \\
\hline None & $3(6.8 \%)$ & $\begin{array}{l}41 \\
(93.2 \%)\end{array}$ & & & & 44 \\
\hline 1 to 3 & $7(5.3 \%)$ & $\begin{array}{l}125 \\
(94.7 \%)\end{array}$ & 149.734 & 4 & 0.0001 & 132 \\
\hline 4 to 6 & $\begin{array}{l}26 \\
(51.0 \%)\end{array}$ & $\begin{array}{l}25 \\
(49.0 \%)\end{array}$ & & & & 51 \\
\hline 7 to 9 & $\begin{array}{l}23 \\
(76.7 \%)\end{array}$ & $7(23.3 \%)$ & & & & 30 \\
\hline 10 and more & $\begin{array}{l}27 \\
(96.4 \%)\end{array}$ & $1(3.6 \%)$ & & & & 28 \\
\hline \multicolumn{7}{|c|}{ Treatment Option } \\
\hline $\begin{array}{l}\text { Nicotine } \\
\text { Replacement } \\
\text { Therapy }\end{array}$ & $\begin{array}{l}30 \\
(34.5 \%)\end{array}$ & $\begin{array}{l}57 \\
(65.5 \%)\end{array}$ & 1.103 & 1 & 0.327 & 87 \\
\hline $\begin{array}{l}\text { Non-medical } \\
\text { therapy }\end{array}$ & $\begin{array}{l}56 \\
(28.3 \%)\end{array}$ & $\begin{array}{l}142 \\
(71.7 \%)\end{array}$ & & & & 198 \\
\hline
\end{tabular}

${ }^{\text {a }}$ Mean (SD).

b Independent T-test.

c Fisher's Exact Test.

model showed a good Receiver Operating Characteristic (ROC) curve with area under the curve (AUC) of $0.96 \%$ (95\% CI $0.94-0.98$ ), as suggested by Fig. 1.

\section{Discussion}

Smoking cessation remains as a challenge not only to healthcare personnel but also to the smoker who attempted it. However, this study showed a good proportion (30.2\%) of quit smoking success among those enrolled in public facilities' "Quit Smoking Clinic" - at Seremban district. The figure is in line with the national target ( $>30 \%$ success) set by the Ministry of Health ( $\mathrm{MOH})$, as a measure to reduce the mortality burden attributed to tobacco. Nevertheless, the figure obtained from this study and the target set to achieved is almost similar to the rate of smoking cessation reported in the USA. ${ }^{12}$ Although the number is 
Table 4

Multiple logistic regression.

\begin{tabular}{|c|c|c|c|c|c|c|c|c|c|c|}
\hline No & Variable & Crude Odd Ratio (95\% CI) & B & S.E. & Wald & df & Sig. & Adjusted Odd Ratio & UL CI & LL CI \\
\hline \multirow[t]{3}{*}{1} & Treatment Option & & & & & & & & & \\
\hline & NRT & $1.34(0.78,2.29)$ & 1.034 & 0.479 & 4.654 & 1 & 0.031 & 2.811 & 1.099 & 7.189 \\
\hline & Non NRT & 1 & & & & & & 1.00 & & \\
\hline \multirow[t]{3}{*}{2} & Diabetes Mellitus & & & & & & & & & \\
\hline & Yes & $2.64(1.28,5.46)$ & 1.464 & 0.627 & 5.456 & 1 & 0.02 & 4.321 & 1.266 & 14.756 \\
\hline & No & 1 & & & & & & 1.00 & & \\
\hline \multirow[t]{6}{*}{3} & No. of attended appointment & & & & 33.975 & 4 & 0.001 & & & \\
\hline & 10 and more & $369.00(36-46-3735.04)$ & 4.295 & 1.482 & 8.394 & 1 & 0.004 & 73.309 & 4.012 & 1339.534 \\
\hline & 7 to 9 & $44.91(10.58-190.61)$ & 1.873 & 1.136 & 2.715 & 1 & 0.099 & 6.506 & 0.701 & 60.345 \\
\hline & 4 to 6 & $14.21(3.90-51.86)$ & 0.832 & 1.061 & 0.614 & 1 & 0.433 & 2.297 & 0.287 & 18.382 \\
\hline & 1 to 3 & $0.77(0.19-3.10)$ & -1.615 & 1.072 & 2.27 & 1 & 0.132 & 0.199 & 0.024 & 1.626 \\
\hline & Nil & & & & & & & 1.00 & & \\
\hline \multirow[t]{3}{*}{4} & Ethnicity & & & & & & & & & \\
\hline & Malay & $1.58(0.90,2.78)$ & 1.014 & 0.505 & 4.039 & 1 & 0.044 & 2.757 & 1.025 & 7.414 \\
\hline & Others & 1 & & & & & & 1.00 & & \\
\hline 5 & Hypertension & $3.01(1.75,5.18)$ & & & & & & & & \\
\hline 6 & Ischaemic Heart Disease & $3.30(1.11,9.82)$ & & & & & & & & \\
\hline
\end{tabular}

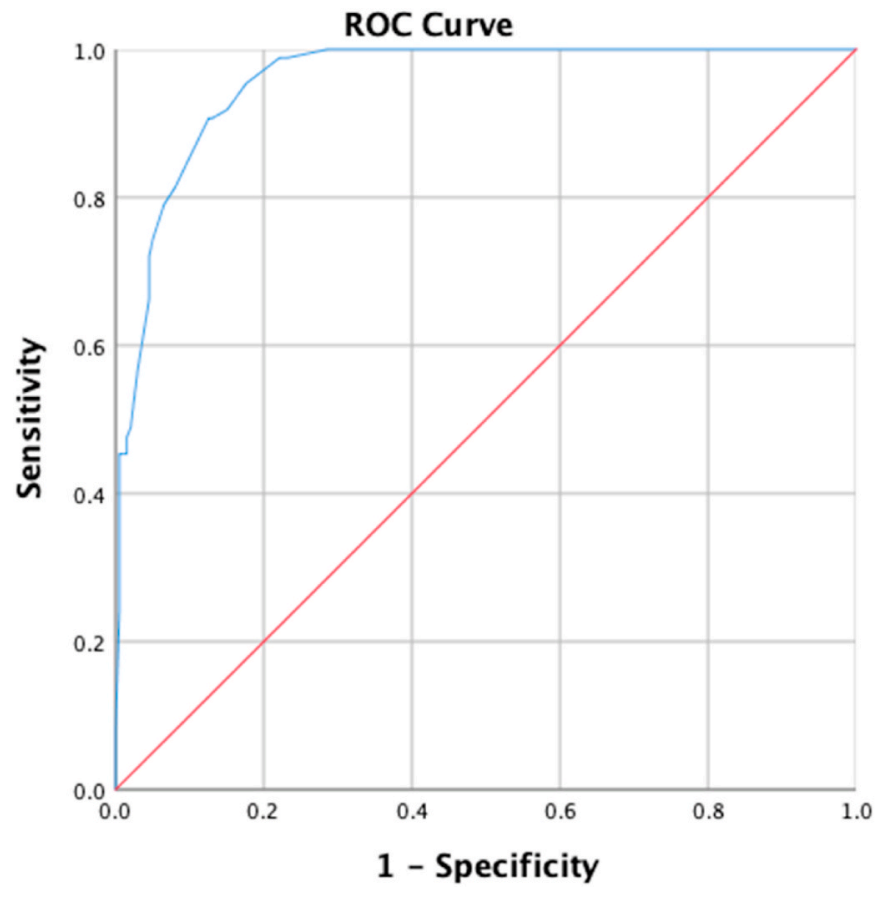

Fig. 1. Receiver operating characteristic (ROC) curve.

encouraging, more effort needs to be put in place to increase quit smoking rate especially among those seeking the service. This is because smoking cessation has always been associated with significant improvement in health outcomes due to the restoration of normal body physiological function.

The finding in this study revealed several predictors of successful quit smoking; the use of nicotine replacement therapy (NRT), frequency of appointments attended, presence of diabetes comorbidity, and Malay ethnicity. Nicotine is a compound in tobacco smoke and is the principal modulator for psychopharmacological effects associated with addiction. ${ }^{13}$ Therefore, substituting the nicotine in tobacco with NRT medication will help to ease the physiological and psychological withdrawal symptoms, hence ultimately reducing the motivation to continue smoking. This could be the possible explanation for the difference in the duration to successful quit time between the NRT group and the non NRT group. Apart from that, the use of NRT to aid in the process of quit smoking has been widely available with numerous modalities in the market or upon prescription such as nicotine gum, nicotine lozenge, nicotine tablet, nicotine oral inhaler, nicotine nasal spray and nicotine transdermal patch. ${ }^{14}$ However, in public healthcare settings in Malaysia, the option for treatment is only limited to nicotine patch and nicotine tablets that can only be supplied when registered with "Quit Smoking Clinic". Regardless of any treatment modalities, evidence suggest that NRTs increase the rate of quit smoking by $50 \%-60 \%$ as published by Cochrane library, ${ }^{15}$ which far exceeded our data (34.8\%). Although all the samples were registered in the program, not all were supplied with NRT. Some of the respondents refused NRT early in the program while some discontinued the treatment prematurely. This is not uncommon as literature have reported several reasons such as concern about safety, lack of confidence in efficacy, the perception of being in a highly addictive state, as well as fear of the side effect and relapses. ${ }^{16,17}$

We also found that smokers who attend more "Quit Smoking Clinic" appointments performed better in term of successful smoking cessation rate as compared to those who attended only a few. It is possible that sessions with medical personnel during the visit increases their motivation and will power to quit smoking. More importantly, these medical personnel have undergone extensive training of the module prior to running the Quit Smoking Clinic, which was based on the Transtheoretical model (TTM) of behaviour change. The model was elucidated and validated by Prochaska and colleague following rigorous study of more than 300 theories in psychotherapy and behaviour since over the last 30 years. ${ }^{18}$ According to TTM, a change in behaviour occurs in stages, namely precontemplation, contemplation, preparation, action, and maintenance together with a concept of relapse stage that may set one back to earlier stage. ${ }^{19}$ In addition to this, TTM extensively illuminates in depth the ten processes of change, two decisional balance and three temptation domains (social situation, craving/habitual, and negative affect situation). As such, TTM has been widely employed in quit smoking program all over the world, ${ }^{20-22}$ despite other literature reporting au contraire. ${ }^{23}$

Our finding suggest that presence of diabetes is a strong predictor to successful quit smoking. The result might differ from the study done in South Korea ${ }^{24}$ but this could be a good sign to the setting. At the moment, the country is facing increased prevalence of both diabetes and smoking. On top of that, the presence of diabetes among smoker is very alarming from the synergistic interaction effect. For example, the joint effect of diabetes and smoking caused a pooled relative risk of 1.55 for total mortality and 1.45 relative risk for cardiovascular mortality. ${ }^{25}$ This figure concurred with earlier studies that showed overall increment of mortality risk in those who both smoke and have diabetes. ${ }^{26}$ Therefore, vigorous promotional activities need to be targeted to this population to prevent the adverse outcome. Apart from that, we found that other comorbidities such as hypertension and ischaemic heart disease (IHD) were confounders in this study. This is plausible as smoking is a risk factor for hypertension and both have a strong association with IHD. 
Despite older age being a statistically significant predictor to quit smoking in bivariate analysis, the variable was not a significant predictor upon multivariable analysis. The finding is different from previously reported studies that proposed several reasons for a higher chance of quit smoking in older age. ${ }^{27}$ The difference in results could arise from the dissimilarity of sample size, in which the current study is only one tenth in its size. Therefore, more data may be needed to compare gender differences in smoking cessation success.

This study has some limitations. Firstly, the use of registry (tabulated data) may limit other potential predictors to be included in the analysis. Socioeconomic variables were unable to be included despite literature suggested some contribution towards smoking cessation. ${ }^{24,28}$ Secondly, the outcome measured (smoking cessation) was measured based on self-report without biochemical verification. This method tends to be skewed in smoking behaviour due to subject recall bias and social desirability bias. ${ }^{29,30}$ In addition to this, our study was only limited to those seeking treatment in public healthcare facilities which may not reflect the other spectrum of people who successfully quit smoking in the private sector. Therefore, it is necessary to exercise caution when attempt is made to generalise the findings for the whole country.

\section{Conclusion}

In summary, the rate of smoking cessation among smokers utilising "Quit Smoking Clinic" in Seremban public health facilities is good (30.2\%) and comparable to worldwide data. Treatment with NRT, frequency of attending appointments, being Malay ethnicity and comorbidity of diabetes were significantly associated with rate of smoking cessation. Hence, these predictors can be used by the Seremban health authority to design specific interventions to enhance rates of smoking cessation among the population.

\section{Declaration of competing interest}

A conflict of interest occurs when an individual's objectivity is potentially compromised by a desire for financial gain, prominence, professional advancement or a successful outcome. CEGH Editors strive to ensure that what is published in the Journal is as balanced, objective and evidence-based as possible. Since it can be difficult to distinguish between an actual conflict of interest and a perceived conflict of interest, the Journal requires authors to disclose all and any potential conflicts of interest.

\section{References}

1 WHO WHO. Tobacco [cited 2021 Apr 14]. Available from: https://www.who.int/ news-room/fact-sheets/detail/tobacco; 2020.

$2 \mathrm{Lim} \mathrm{KH}$, Teh $\mathrm{CH}$, Nik Mohamed MH, et al. Exposure to tobacco secondhand smoke and its associated factors among non-smoking adults in smoking-restricted and nonrestricted areas: findings from a nationwide study in Malaysia. BMJ Open. 2018 Jan 1;8(1) [cited 2021 Apr 14] https://pubmed.ncbi.nlm.nih.gov/29317411/. Available from:.

3 Services USD of H and H. Prevention C for DC and, promotion NC for CDP and H, health $O$ on $S$ and. Executive summary (the health consequences of smoking-50 Years of progress: a report of the surgeon general) [cited 2021 Apr 14]. 2014:1-36. Available from: papers2:.

4 Singhavi H, Ahluwalia JS, Stepanov I, Gupta PC, Gota V, Chaturvedi P, et al. Tobacco carcinogen research to aid understanding of cancer risk and influence policy [cited 2021 Apr 14] Laryngoscope Invest Otolaryngol. 2018 Oct;3(5):372-376. Available from:/, pmc/articles/PMC6209619/.

5 Rakel RE, Company WBS, London P, York N, Louis S, Toronto S. In: TEXT BOOK OF FAMILY PRACTICE. ninth ed. 2016.

$6 \mathrm{Wu} \mathrm{J}$, Sin DD. Improved patient outcome with smoking cessation: when is it too late? Int J COPD. Int J Chron Obstruct Pulmon Dis. 2011;6:259-267 [cited 2021 Apr 14] htt ps://pubmed.ncbi.nlm.nih.gov/21814462/. Available from:.

7 Bagcchi S, BMJ (Clinical research. Eleven Asian countries pledge tougher action on tobacco [cited 2021 Apr 14]. In: British Medical Journal Publishing Group. vol. 351. 2015:h4896. Available from: https://www.bmj.com/content/351/bmj.h4896.

8 World Health Organization. Tobacco free initiative [Internet], [cited 2021 Apr 14] http://www.emro.who.int/tfi/mpower/index.html; 2016. Available from:, 1.
9 Lee MY, Tam CL, Tam C-L. Smoking and burden of ill health: a review of the Malaysian context. In: International Journal of Collaborative Research on Internal Medicine \& Public Health. iMedPub. vol. 6. 2014 [cited 2021 Apr 14]. Available from: https://interna lmedicine.imedpub.com/smoking-and-burden-of-ill-health-a-review-of-themala ysian-context.php?aid=6423.

10 Kim YJ. Predictors for successful smoking cessation in Korean adults. Asian Nurs Res. 2014;8(1):1-7 [cited 2021 Apr 14], Available from: https://pubmed.ncbi.nlm.nih. gov/25030486/.

11 Hosmer Jr DW, Lemeshow S XS. In: Applied Logistic Regression. third ed. Wiley; 2013: 528 [cited 2021 Apr 15] https://www.wiley.com/en-us/Applied+Logistic+Reg ression\%2C+3rd+Edition-p-9780470582473. Available from:.

12 Goren A, Annunziata K, Schnoll RA, Suaya JA. Smoking cessation and attempted cessation among adults in the United StatesGarcía AV, ed. PLoS One. 2014;vol. 9(3), e93014. Mar 27 [cited 2021 Apr 13] https://dx.plos.org/10.1371/journal.pon e.0093014. Available from:

13 Centers for Disease Control and Prevention (US). Nicotine addiction: past and present - how tobacco smoke causes disease: the biology and behavioral basis for smokingattributable disease [cited $2021 \mathrm{Apr}$ 13]. Available from: https://www.ncbi.nlm.nih. gov/books/NBK53018/.

14 Wadgave U, Nagesh L. Nicotine replacement therapy: an overview [cited 2021 Apr 13] Int J Health Sci Renaissance Med Publ. 2016;10:425-435. Available from:/, pmc/ articles/PMC5003586/.

15 Hartmann-Boyce J, Chepkin SC, Ye W, Bullen C, Lancaster T. Nicotine replacement therapy versus control for smoking cessation. Cochrane Database Syst Rev John Wiley and Sons Ltd. 2018;2018 [cited 2021 Apr 13]. Available from: https://www.cochr anelibrary.com/cdsr/doi/10.1002/14651858.CD000146.pub5/full.

16 Shiffman S, Ferguson SG, Rohay J, Gitchell JG. Perceived safety and efficacy of nicotine replacement therapies among US smokers and ex-smokers: relationship with use and compliance [cited 2021 Apr 13] Addiction. 2008 Aug;103(8):1371-1378. Available from: https://pubmed.ncbi.nlm.nih.gov/18855827/.

17 Lee PN, Fariss MW. A systematic review of possible serious adverse health effects of nicotine replacement therapy [cited 2021 Apr 13] Arch Toxicol Springer Verlag. 2017; 91:1565-1594. Available from:/, pmc/articles/PMC5364244/.

18 Prochaska JO, Velicer WF. The transtheoretical model of health behavior change. Am $J$ Health Promot. 1997;12(1):38-48 [cited 2021 Apr 14] https://pubmed.ncbi.nlm. nih.gov/10170434/. Available from:

19 Glanz K, Rimer Bk, Viswanath K. Health Behaviour and Health Education: Theory, Research, and Practice. 2002.

20 Spencer L, Pagell F, Hallion ME, Adams TB. Applying the transtheoretical model to tobacco cessation and prevention: a review of literature [Internet]. Am J Health Promotion Am J Health Promotion. 2002;17:7-71 [cited 2021 Apr 13] http://journals. sagepub.com/doi/10.4278/0890-1171-17.1.7. Available from:.

21 Campbell S, Bohanna I, Swinbourne A, Cadet-James Y, Mckeown D, McDermott R. Stages of change, smoking behaviour and readiness to quit in a large sample of indigenous australians living in eight remote North Queensland communities [cited 2021 Apr 13] Int J Environ Res Publ Health. 2013 Apr;10(4):1562-1571. Available from:/, pmc/articles/PMC3709334/.

22 Siewchaisakul P, Luh DL, Chiu SYH, Yen AMF, Chen CD, Chen HH. Smoking cessation advice from healthcare professionals helps those in the contemplation and preparation stage: an application with transtheoretical model underpinning in a community-based program. Tob Induc Dis. 2020 Jul 1;18(July). https://doi.org/ 10.18332/tid/123427 [cited 2021 Apr 13], Available from:.

23 Aveyard P, Massey L, Parsons A, Manaseki S, Griffin C. The effect of Transtheoretical Model based interventions on smoking cessation. Soc Sci Med. 2009 Feb;68(3): 397-403 [cited 2021 Apr 13] https://pubmed.ncbi.nlm.nih.gov/19038483/. Available from:.

24 Kim Y, Cho WK. Factors associated with successful smoking cessation in Korean adult males: findings from a national survey [cited 2021 Apr 14] Iran J Public Health. 2014 Nov 9;43(11):1486-1496. Available from:/pmc/articles/PMC4449497/.

25 Pan A, Wang Y, Talaei M, Hu FB. Relation of smoking with total mortality and cardiovascular events among patients with diabetes mellitus: a meta-analysis and systematic review. Circul Lippincott Williams and Wilkins. 2015;132:1795-1804. cited 2021 Apr 14] https://pubmed.ncbi.nlm.nih.gov/26311724/. Available from:.

26 Qin R, Chen T, Lou Q, Yu D. Excess risk of mortality and cardiovascular events associated with smoking among patients with diabetes: meta-analysis of observational prospective studies. Int J Cardiol. 2013 Jul 31;167(2):342-350 [cited 2021 Apr 14] https://pubmed.ncbi.nlm.nih.gov/22251416/. Available from:.

27 Lim KH, Heng PP, Nik Mohamed MH, et al. Prevalence and factors associated with attempts to quit and smoking cessation in Malaysia. Asia Pac J Publ Health. 2019 Oct 1;31(7_suppl):22S-31S [cited 2021 Apr 14] http://journals.sagepub.com/doi/10.11 77/1010539519874944. Available from:.

28 Feng G, Jiang Y, Li Q, et al. Individual-level factors associated with intentions to quit smoking among adult smokers in six cities of China: findings from the ITC China Survey. Tobac Contr. 2010 Oct 1;19 Suppl 2(Suppl 2):i6-11 [cited 2021 Apr 14] http://tobaccocontrol.bmj.com/. Available from:.

29 Benowitz NL, Bernert JT, Foulds J, et al. Biochemical verification of tobacco use and abstinence: 2019 update. Nicotine and Tobacco Res Oxford Univ Press. 2020;22: 1086-1097 [cited 2021 Apr 14], Available from:/pmc/articles/PMC7882145/.

30 Wee LH, Shahab L, Bulgiba A, West R. Stop smoking clinics in Malaysia: characteristics of attendees and predictors of success. Addict Behav. 2011 Apr;36(4): 400-403 [cited 2021 Apr 14] https://linkinghub.elsevier.com/retrieve/pii/S030 6460310003321. Available from:. 